\title{
Naïve Regulatory T Cell Subset Is Altered in X-Linked Agammaglobulinemia
}

\begin{abstract}
Pavel V. Shelyakin ${ }^{1}$, Ksenia R. Lupyr ${ }^{1,2}$, Evgeny S. Egorov' ${ }^{1}$, llya A. Kofiadi ${ }^{3}$, Dmitriy B. Staroverov ${ }^{1,4}$, Sofya A. Kasatskaya ${ }^{1,2,4}$, Valeriia V. Kriukova ${ }^{1,2}$, Irina A. Shagina ${ }^{1,4}$, Ekaterina M. Merzlyak ${ }^{1,4}$, Tatiana O. Nakonechnaya ${ }^{4}$, Elena A. Latysheva ${ }^{3}$, Irina A. Manto ${ }^{3}$, Musa R. Khaitov ${ }^{3}$, Sergey A. Lukyanov ${ }^{4}$, Dmitriy M. Chudakov ${ }^{1,2,4}$ and Olga V. Britanova ${ }^{1 *}$

1 Shemyakin-Ovchinnikov Institute of Bioorganic Chemistry, Russian Academy of Sciences, Moscow, Russia, ${ }^{2}$ Center of Life Sciences, Skolkovo Institute of Science and Technology, Moscow, Russia, ${ }^{3}$ FSBI "NRC Institute of Immunology" FMBA of Russia, Moscow, Russia, 4 Institute of Translational Medicine, Pirogov Russian National Research Medical University, Moscow, Russia
\end{abstract}

\section{OPEN ACCESS}

Edited by:

Osamu Takeuchi,

Kyoto University, Japan

Reviewed by:

Joana Dias,

Vaccine Research Center (NIAID),

United States

Hideki Ueno,

Kyoto University, Japan

*Correspondence:

Olga V. Britanova

olbritan@gmail.com

Specialty section:

This article was submitted to

Antigen Presenting Cell Biology,

a section of the journal

Frontiers in Immunology

Received: 19 April 2021

Accepted: 29 July 2021

Published: 19 August 2021

Citation:

Shelyakin PV, Lupyr KR, Egorov ES, Kofiadi IA, Staroverov DB, Kasatskaya SA, Kriukova W, Shagina IA, Merzlyak EM, Nakonechnaya TO, Latysheva EA, Manto IA, Khaitov MR, Lukyanov SA,

Chudakov DM and Britanova OV

(2021) Naive Regulatory T Cell

Subset is Altered in X-Linked Agammaglobulinemia.

Front. Immunol. 12:697307. doi: 10.3389/fimmu.2021.697307
The interplay between $\mathrm{T}$ - and B-cell compartments during naïve, effector and memory $\mathrm{T}$ cell maturation is critical for a balanced immune response. Primary B-cell immunodeficiency arising from $X$-linked agammaglobulinemia $(X L A)$ offers a model to explore $B$ cell impact on $T$ cell subsets, starting from the thymic selection. Here we investigated characteristics of nailve and effector T cell subsets in XLA patients, revealing prominent alterations in the corresponding T-cell receptor (TCR) repertoires. We observed immunosenescence in terms of decreased diversity of naïve $\mathrm{CD}^{+}$and $\mathrm{CD} 8^{+}$TCR repertoires in XLA donors. The most substantial alterations were found within naive $\mathrm{CD} 4^{+}$subsets, and we have investigated these in greater detail. In particular, increased clonality and convergence, along with shorter CDR3 regions, suggested narrower focused antigen-specific maturation of thymus-derived naïve $\mathrm{T}_{\text {reg }}\left(\mathrm{CD} 4^{+} \mathrm{CD} 45 \mathrm{RA} \mathrm{A}^{+} \mathrm{CD} 27^{+} \mathrm{CD} 25^{+}\right)$in the absence of $\mathrm{B}$ cells normally presenting diverse self and commensal antigens. The naive $T_{\text {reg }}$ proportion among naïve CD4 T cells was decreased in XLA patients, supporting the concept of impaired thymic naïv $T_{\text {reg }}$ selection. Furthermore, the naive $T_{\text {reg }}$ subset showed prominent differences at the transcriptome level, including increased expression of genes specific for antigen-presenting and myeloid cells. Altogether, our findings suggest active B cell involvement in CD4 T cell subsets maturation, including B cell-dependent expansion of the naiive Treg TCR repertoire that enables better control of self-reactive T cells.

Keywords: X-linked agammaglobulinemia (XLA), TCR repertoire, T cell gene expression, naïve regulatory T cells, CDR3 $\beta$ features

\section{INTRODUCTION}

Classical functions of B lymphocytes include antigen presentation, antibody secretion, co-stimulation of $\mathrm{CD}^{+}{ }^{+} \mathrm{T}$ cells, and crosstalk with innate and adaptive $\mathrm{T}$ cells (1). However, the role of B cells in the maturation of T cell subsets is not fully understood. Certain B cell subsets have been shown to be involved in the negative selection of $\mathrm{T}$ cells in the thymus, suggesting a role for 
$B$ cells in the induction and maintenance of self-tolerance (2-4). The thymic population of $\mathrm{B}$ cells constitutes approximately $0.1-0.3 \%$ of thymocytes-comparable to the number of dendritic cells in the thymus (3). It is highly likely that thymic $\mathrm{B}$ cells, including those migrating from the periphery (5) involved in the formation of the $\mathrm{T}$ cell receptor (TCR) repertoire of naïve $\mathrm{CD}^{+} \mathrm{T}$ cells $(3,4)$. Further interaction of $\mathrm{B}$ and $\mathrm{T}$ cells could shape the TCR repertoire of both naive and effector memory $\mathrm{T}$ cells in the periphery. Most studies of TCR repertoires in immune pathologies have focused on $\mathrm{T}$ cell deficiencies, such as severe combined immunodeficiency (SCID), Omenn's syndrome, and Wiskott-Aldrich syndrome (6). A considerable decrease in the diversity of the total TCR repertoire, a biased $\mathrm{CD} 4 / \mathrm{CD} 8$ ratio, and weak proliferative activity of $\mathrm{T}$ cells in response to antigenic stimulation have all been reported for these diseases $(6,7)$. $\mathrm{X}$-linked agammaglobulinemia (XLA) is a primary immunodeficiency disorder characterized by low levels or absence of immunoglobulins and mature B cells. The pathogenesis of XLA is associated with a loss-of-function mutation in a single gene, Btk (Bruton's tyrosine kinase), resulting in the arrest of $\mathrm{B}$ cell differentiation in the bone marrow at the pre-B cell stage. This makes XLA a classical single-factor model to explore the impact of B cell deficiency on $\mathrm{T}$ cell immunity. XLA remains understudied in terms of changes in the $\mathrm{T}$ cell compartment of the adaptive immune system, but previous studies have demonstrated $\mathrm{V}$ gene segment usage differences and increased CDR3 sharing in TCR repertoires for the bulk $\mathrm{T}$ cell population in XLA patients compared to healthy donors (8).

We have explored the TCR repertoire of naïve and memory $\mathrm{CD}^{+}$and $\mathrm{CD}^{+} \mathrm{T}$ lymphocytes as well as several functional naïve $\mathrm{CD}^{+}\left(\mathrm{nCD} 4^{+}\right)$subsets in XLA and age-matched healthy young donors. The heterogeneous naïve $\mathrm{CD} 4^{+}$population includes naïve $\mathrm{T}_{\text {regs }}$ and recent thymic emigrants (RTEs), which represent $\mathrm{T}$ cell subsets with rather distinct intrinsic properties $(9,10)$. Before post-thymic selection, the TCR repertoire of RTEs is relatively enriched for self-reactive TCRs. Self-reactive RTEs are predisposed to immune tolerance or anergy, and thus undergo final selection in the periphery. In inflammatory conditions, however, tolerance-prone RTE cells are able to convert into highly competent effector cells (11). $\mathrm{T}_{\text {reg }}$ cells were originally identified within the $\mathrm{CD} 4{ }^{+} \mathrm{CD} 25^{+} \mathrm{T}$ cell subset, which plays a pivotal role in self-tolerance and prevents autoimmune response (12). Notably, both naïve and effector $\mathrm{T}_{\text {reg }}$ subsets display TCR repertoire features associated with high selfreactivity and high affinity, which distinguishes $\mathrm{T}_{\text {regs }}$ from other subsets and indicates their cell fate determination during thymic selection $(13,14)$.

It has been reported that high rates of infectious diseases in XLA patients $(15,16)$ can drive early immunosenescence in their $\mathrm{T}$ cell populations. To address the potential impact of natural immunosenescence, we completed the analysis with data from healthy elderly repertoires. We observed a reduced proportion of naïve $\mathrm{T}_{\text {reg }}$ cells among the $\mathrm{nCD}^{+}$subset, along with high convergence and reduced diversity of naïve $T_{\text {reg }}$ TCR repertoires in XLA donors compared to healthy young cohorts. These findings indicate that naive $\mathrm{T}_{\text {reg }}$ selection and homeostasis might be impaired in XLA patients. In B cell-deficient mouse models, naïve $\mathrm{T}_{\text {regs }}$ have been shown to have reduced proliferative capacity and ability to suppress effector cells (17). In parallel, the negative selection of highly autoreactive $\mathrm{T}$ cells might be impaired in the absence of a thymic $B$ cell population $(3,4)$. Several studies in mice have shown that expansion of natural $\mathrm{T}_{\text {reg }}$ subsets is dependent upon thymic $\mathrm{B}$ cells, which can shape $\mathrm{T}_{\text {reg }}$ TCR repertoires via TCR-pMHCII interaction (18, 19). Together with thymic dendritic and epithelial cells, thymic $B$ cells have been shown to induce natural $\mathrm{T}_{\text {reg }}$ development and proliferation (19).

Our findings support active involvement of the $B$ cell population in naïve $\mathrm{T}_{\text {reg }}$ selection and homeostasis, and imply a possible link between susceptibility to the development of autoimmune and inflammatory diseases in XLA patients (15, 16) and the proportional reduction of naïve $T_{\text {reg }}$ cells, combined with the alteration of naive $\mathrm{CD} 4^{+}$and naïve $\mathrm{T}_{\text {reg }} \mathrm{TCR}$ repertoires and naïve $\mathrm{T}_{\text {reg }}$ transcriptional programs.

\section{MATERIAL AND METHODS}

\section{Patients and Healthy Donors}

XLA and healthy donors were informed of the final use of their blood and signed an informed consent document. The study was approved by the local ethics committee, NRC Institute of Immunology FMBA (Moscow, Russia), protocol 6-1, 09 June 2020, and conducted in accordance with the Declaration of Helsinki. The 10 XLA patients (age 18-36) and a cohort of 15 young donors (age 22-35) and 6 old donors (age 49-83) (Supplemental Table 1) were enrolled in the study. All donors were males. Individuals with previously diagnosed cancer or severe autoimmune disease were excluded. The same exclusion criteria were applied to the control cohort. One XLA donor had rheumatoid arthritis affecting both hips, both knees, the right ankle, both wrists, and the metacarpophalangeal joint of the right first finger of the left hand, with ankylosis of the left hip joint, aseptic necrosis of the head of the right femur, and fibrous contracture of the right ankle joint. The other donors had no signs of autoimmune or inflammatory conditions. The baseline treatment for XLA patients included IVIG therapy $(0.4 \mathrm{~g} / \mathrm{kg})$. We performed immunophenotyping analysis and verified the lack of CD19 expression on XLA PBMCs (Supplemental Figure 5).

\section{Cell Sorting}

Peripheral blood (12-20 ml) was collected into a number of EDTA-treated Vacutainer tubes (BD Biosciences, Franklin Lakes). For cell sorting of $\mathrm{CD}^{+}$and $\mathrm{CD}^{+}$(defined as $\mathrm{CD}^{+}$ $\mathrm{CD}^{-}$) memory and naïve T cells, $\mathrm{RTE}, \mathrm{mnCD} 4+$, naïve Treg we used a strategy previously described in Ref (20). Further details see in Supplemental Methods. Number of sorted cells for each population see in Supplemental Tables 2, 3. All cell populations were collected directly into the RLT buffer (Qiagen) and stored at $-70 \mathrm{C}$. 


\section{RNA Isolation and cDNA Library Preparation}

Total RNA was isolated using the RNeasy mini kit (Qiagen) according to the manufacturer's instructions. In all experiments described here, cDNA libraries were obtained using 5'-RACE with unique molecular identifiers (UMI) (20) using Human TCR profiling kit (MiLaboratory LLC). Libraries were sequenced on Illumina NextSeq 500 using 300 cycle reagent kit, paired-end $150+$ 150 nt mode.

\section{Sequencing and Data Analysis}

Raw sequencing data was analyzed using MIGEC software v.1.2.9 (21). UMI-labeled TCR $\beta$ cDNA molecules were obtained per sample with at least $\sim 1$ read per UMI (Supplemental Tables 2, 3). Analysis of the averaged CDR3 characteristics was performed weighted by the abundance of each clonotype. All of the physicochemical characteristics were calculated and averaged for the five amino acid residues located in the middle of CDR3, which are considered to have the highest probability to contact with peptide-MHC complex (20). Further details see in Supplemental Methods.

\section{Statistical Analysis}

Statistical analysis was performed on processed datasets with $\mathrm{R}$. Clonotype CDR3 features were calculated for the most frequent $\mathrm{V}$ segments extracted from full clone sets to avoid bias related to a particular TRBV segment's contribution to CDR3 analysis and individual differences in $\mathrm{V}$ segment usage. In case of diversity estimation all $\mathrm{V}$ segment subsets within the same cell type were down-sampled to the same number of UMI. To exclude potential dependence of clonotype features from the $\mathrm{V}$ segment, all features within the same cell type and the same V segment were turned to $\mathrm{Z}$-scores as described in (20). To compare the medians between three groups of samples the Kruskal-Wallis test was used followed by Dunn test with the Benjamini-Hochberg correction for multiple testing, if not mentioned otherwise. To compare the medians between two groups of samples the Wilcoxon rank sum test was applied. Further details see in Supplemental Methods. The data is available by PRJNA752656 in the SRA (NCBI).

\section{RNAseq Library Preparation and Analysis}

RNA was isolated using the RNeasy Micro Kit (Qiagen) and analyzed using a Qubit 2.0 Fluorometer (Thermo Fisher Scientific). cDNA libraries were prepared with SMART-Seq v4 Ultra Low Input Kit for Sequencing (Takara Bio). The samples were sequenced using a HiSeq 4000 (75 bp, 10 million average paired reads per sample). Further details see in Supplemental Methods and Supplemental Table 4.

\section{RESULTS AND DISCUSSION}

\section{Deficiency of Naïve $T_{\text {reg }}$ Cells in XLA Patients}

We first assessed the relative abundance of naïve $T$ cells overall as well as distinct naïve $\mathrm{T}$ cell subsets in PBMCs collected from seven young (18-36 years old) male XLA patients and five healthy sex- and age-matched donors (Supplemental Table 1, Figure 1, Supplemental Figure 1A). The percentages of naïve $\mathrm{CD} 4^{+} \mathrm{T}$ cells were comparable for the XLA and healthy cohorts (Figure 1B). The nCD $4^{+}$lymphocyte population was subdivided into naïve $\mathrm{T}_{\text {reg }}\left(\mathrm{CD} 4^{+} \mathrm{CD} 27^{+} \mathrm{CD} 45 \mathrm{RA}^{+} \mathrm{CD} 25^{+}\right)$, mature naïve $\mathrm{CD}^{+}{ }^{+}\left(\mathrm{mnCD}^{+}\right.$; $\left.\mathrm{CD} 4^{+} \mathrm{CD} 27^{+} \mathrm{CD} 45 \mathrm{RA}^{+} \mathrm{CD} 25^{-} \mathrm{CD} 31^{-}\right)$, and $\mathrm{CD} 1^{+}$cells enriched with recent thymic emigrants (RTE; $\mathrm{CD} 4^{+} \mathrm{CD} 27^{+} \mathrm{CD} 45 \mathrm{RA}^{+} \mathrm{CD} 25^{-} \mathrm{CD}^{+} 1^{+}$) (20). Notably, the proportion of naïve $\mathrm{T}_{\text {regs }}$ among $\mathrm{nCD}^{+} \mathrm{T}$ cells was prominently decreased in the XLA cohort (Figure 1C) in contrast to RTEs and $\mathrm{mnCD}^{+}$cells (Figures 1D, E). Low $\mathrm{T}_{\text {reg }}$ counts were previously reported in PBMCs from children with XLA (22) and in spleen of the B cell deficient mice (17). Our data indicate that in the condition associated with primary $\mathrm{B}$ cell deficiency, the generation of $\mathrm{T}_{\text {reg }}$ subsets may be undermined at the level of naïve $\mathrm{T}_{\text {reg }}$ production.

\section{Altered TCR Repertoires of Naïve and Memory T Cells}

Several studies $(23,24)$ have demonstrated that the naïve $\mathrm{T}$ cell subset is not meaningfully affected at the cellular level in XLA patients. However, the impact of a lack of B cells on TCR repertoire selection has not been deeply explored. To investigate this, we performed unique molecular identifier (UMI)-based 5'-RACE TCR $\beta$ profiling, and compared repertoire characteristics for the sorted naïve and memory $\mathrm{CD} 4^{+}$and $\mathrm{CD}^{+} \mathrm{T}$ cells of young XLA patients versus young and old (49-83 y.o.) healthy donors (Supplemental Figures 1B, C and Supplemental Table 2). To increase the statistical power of analysis, we separately compared diversity metrics for the dominant TRBV segments after down-sampling to an equal number of UMI-labeled TCR $\beta$ cDNA molecules, as described in (20).

We assessed normalized diversity metrics, which estimate the evenness of clonotype frequency distribution (i.e., normalized Shannon-Wiener) and the richness of the repertoire based on the number of clonotypes that occur once or twice (i.e. Chao1). We observed a decline in Chaol and normalized Shannon-Wiener diversity values for the $\mathrm{nCD} 4^{+} \mathrm{TCR} \beta$ repertoires of young XLA patients compared to sex- and age-matched healthy donors (Figures 2A, B). In this respect, the naïve $\mathrm{CD}^{+} \mathrm{TCR}$ repertoire of XLA patients reflected a pattern observed in the repertoires of elderly individuals (Figures 2A, B). Similar changes in the elderly cohort were previously linked to thymic involution and continuous and biased peripheral proliferation of naive $\mathrm{T}$ cells in the course of cell niche replenishment at the periphery $(20,25)$. The decrease in TCR diversity for XLA $\mathrm{nCD}^{+}$cells was less prominent (Supplemental Figures 2A, B).

In contrast to the naïve TCR repertoires, we observed more evenly distributed clonotype frequencies in the memory $\mathrm{CD} 4^{+}$ repertoires of XLA patients compared to matched healthy donors (Figure 2B). Previous studies in B cell-deficient mice $(26,27)$ and clinical data from XLA patients (23) have shown that B cells might be required for appropriate $\mathrm{CD}^{+}$activation and the generation and maintenance of pathogen-specific memory 
A

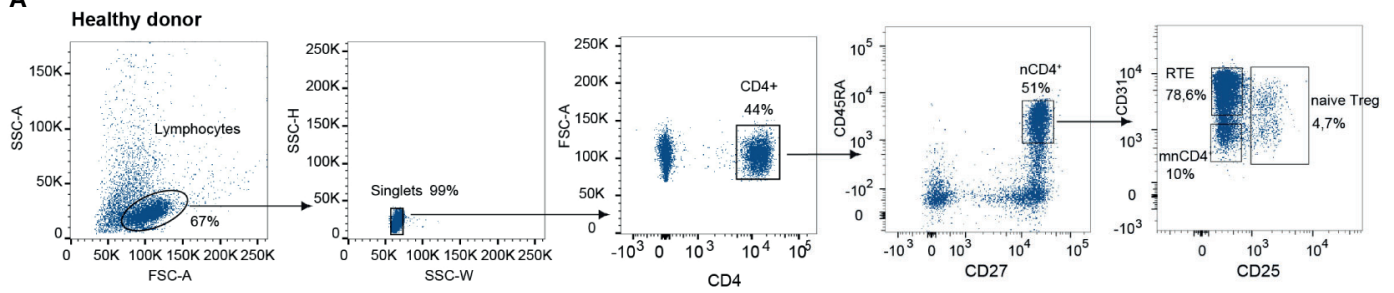

XLA donor

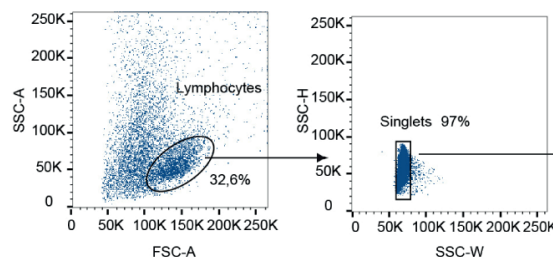

B

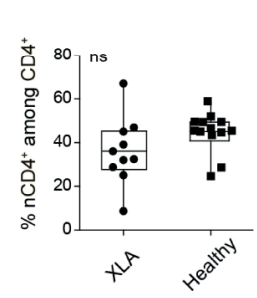

C

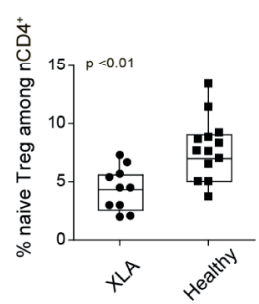

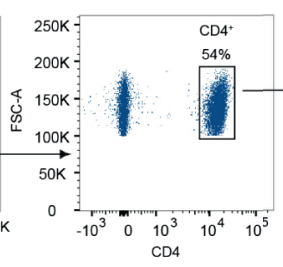

D

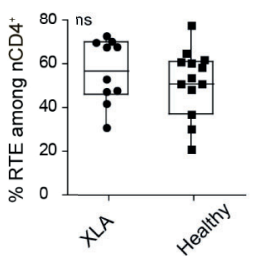

E

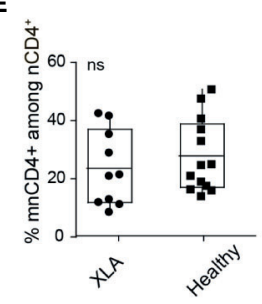

FIGURE 1 | Flow cytometry analysis of CD4+ subsets in healthy and XLA donors. (A) Gating strategy for cell sorting of nCD4+ subsets from healthy (top) and XLA (bottom) young donors, starting from discrimination of lymphocytes by forward (FSC) and side scatter (SSC) profiles and sequential separation of singlets (left), after which $\mathrm{CD}^{+}$cells were selected (middle). $\mathrm{nCD} 4^{+}$were selected as CD45RA ${ }^{+} \mathrm{CD} 27^{+}$, from which RTE, mnCD4 ${ }^{+}$and naïve $\mathrm{T}_{\text {reg }}$ cell subsets were subsequently gated

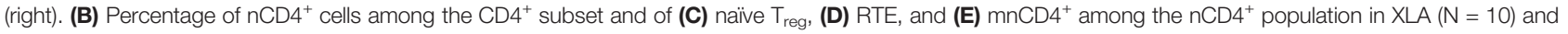
healthy $(\mathrm{N}=13$ ) donors. $p$-values were calculated with the Wilcoxon rank-sum test. NS, non significant.

$\mathrm{T}$ cells. In mice, a lack of B cells results in the deeper depletion of antigen-activated $\mathrm{CD} 4^{+} \mathrm{T}$ cells at the contraction phase, followed by the generation of a smaller number of antigen-specific $\mathrm{CD} 4^{+}$ memory $\mathrm{T}$ cells (28). Significant reduction of $\mathrm{CD} 4^{+}$memory $\mathrm{T}$ cell counts has also been previously reported in XLA donors (23). Thus, the lack of antigen-specific B cell support could contribute to the diminished $\mathrm{T}$ cell memory formation in XLA patients. That being said, other evidence indicates that antigen-specific memory $\mathrm{T}$ cells can be detected years after immunization of XLA patients, similarly to healthy cohorts (29).

Next, we assessed the physicochemical properties of the amino acid residues forming the central part of the CDR3 (Figures 2C, D; Supplemental Figures 2C, D, Figure S3), which primarily interacts with the antigenic peptide within pMHC complexes (20). On average, $\mathrm{nCD}^{+}$and $\mathrm{nCD}^{+}$ CDR3 $\beta$ repertoires of XLA patients contained a higher proportion of "strongly interacting" hydrophobic and aromatic amino acids (F, I, L, M, V, W, and Y; Figure 2C and Supplemental Figure 2C) and bulky amino acid residues (Figure 2D and Supplemental Figure 2D) compared to matched healthy donors. In our previous experience, the average number of strongly interacting amino acid residues is a basic characteristic determining the average features of the CDR3 $\beta$ repertoire $(20,30,31)$. Large numbers of strongly- interacting amino acids may be interpreted as higher average affinity and potentially also increased cross-reactivity of a TCR repertoire (32). The observed increased "strength" in $\mathrm{nCD}^{+}$and $\mathrm{nCD} 4^{+}$repertoires of XLA patients could therefore result from increased competition between naïve $\mathrm{T}$ cells for tonic signaling in the absence of antigen-presenting B cells (33). Notably, the difference in the number of strongly-interacting amino acids was more prominent for the $\mathrm{nCD} 4^{+} \mathrm{T}$ cells compared to the memory $\mathrm{CD}^{+}\left(\mathrm{mCD}^{+}\right) \mathrm{T}$ cell subset. There was no significant difference in CDR3 length or insertion size among the naïve or memory $\mathrm{CD}^{+}$or $\mathrm{CD}^{+} \mathrm{T}$ cell subsets (Supplemental Figure 3 ).

\section{Distinct Properties of Naive CD4 ${ }^{+}$ T Cell Subsets}

Heterogeneous $\mathrm{mnCD}^{+}$, RTE, and naïve $\mathrm{T}_{\text {reg }}$ lymphocyte populations are maintained on the periphery through different mechanisms, and contribute differently to the cumulative landscape repertoire of naïve $\mathrm{CD}^{+} \mathrm{T}$ lymphocytes $(20,34)$. To explore the impact of each naïve $\mathrm{CD}^{+}$subset, we analyzed TCR repertoires of sorted $\mathrm{mnCD} 4^{+}, \mathrm{RTE}$, and naïve $\mathrm{T}_{\text {reg }}$ cell fractions from XLA patients and healthy donors (Figure 3). At least 5,000, 28,000 , and 13,589 cells were sorted for naïve $\mathrm{T}_{\text {reg }}, \mathrm{mnCD}^{+}$, and RTE subsets, respectively (Supplemental Table 3), and UMIbased analysis was performed as above. 
A
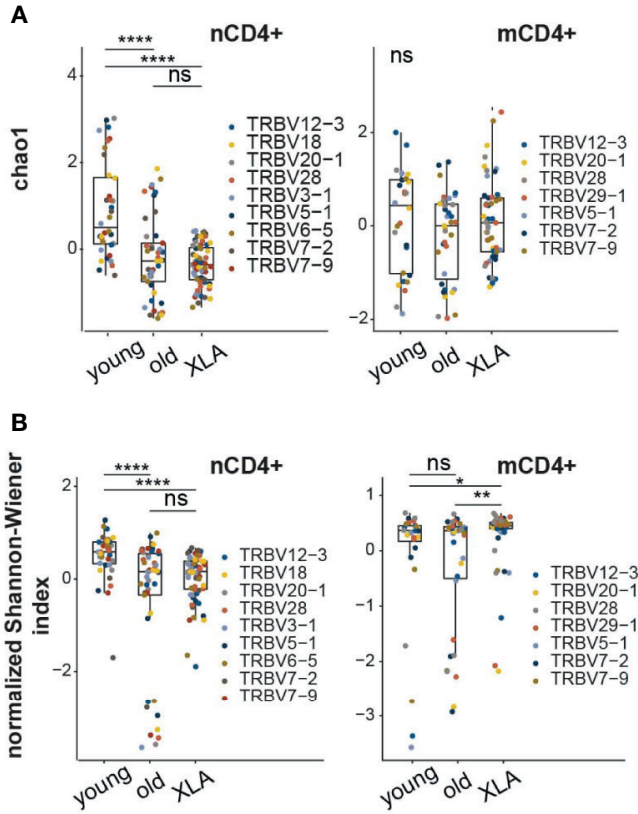

C

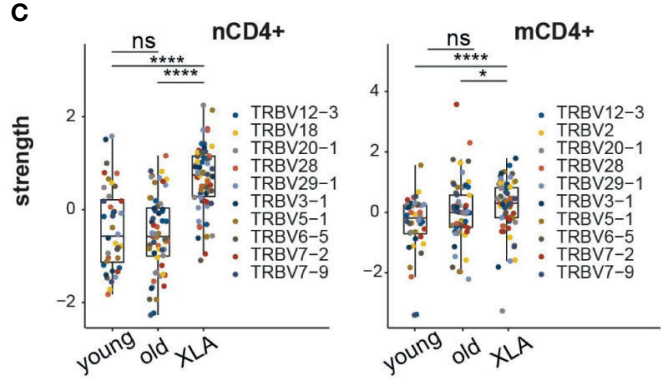

D
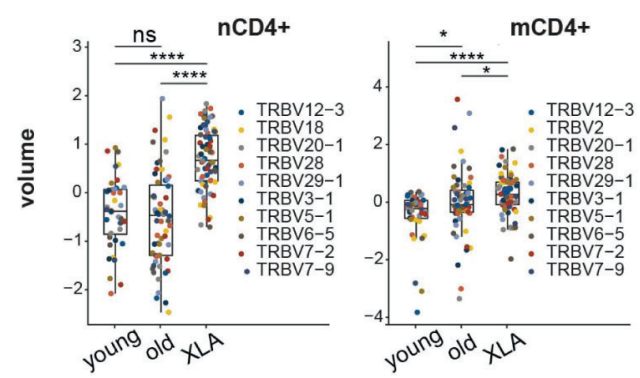

FIGURE 2 | Characteristics of memory and naïve CD4 ${ }^{+}$TCR repertoires in XLA and healthy donors. Analysis of repertoire diversity using the (A) Chao1 index and (B) normalized Shannon-Wiener index. (C) Clonotype interaction strength, as represented by the fraction of hydrophobic and aromatic amino acids, and (D) CDR3 $\beta$ volume, based on bulky amino acids, in the central region of CDR3 from XLA (N=7), and healthy young $(N=6)$ or old $(N=6)$ donors. All analyzed features were calculated for the most abundant $\mathrm{V}$-segments extracted from full clonotype datasets. For diversity analysis, all segment sets were down-sampled to 1,000 randomlychosen UMI-labeled TCR $\beta$ cDNA molecules. Only segments with a sufficient number of UMls were included. To exclude potential dependence of features from the $V$ segment, all features within the same cell type and the same $V$ segment were turned to Z-scores. Differences between groups were examined using the KruskalWallis test followed by the Dunn test with the Benjamini-Hochberg correction. ${ }^{\star} p<0.05$, ${ }^{\star \star} p<0.01$, ${ }^{\star \star \star \star} p<0.0001$, ns, non significant.

For the elderly donors, and to a higher extent for the XLA patients, we observed increased convergence as measured by the relative number of distinct nucleotide sequence variants for each amino acid CDR3 sequence. This effect was observed for all subsets but was more prominent for the naive $\mathrm{T}_{\text {reg }}$ cells (Figure 3A). The latter subset was also characterized by increased clonality in XLA patients, reflected by a decreased normalized Shannon-Wiener index (Figure 3B) but a smaller proportion of shared public clonotypes (Figure 3C). Such features of XLA patients' naïve $T_{\text {reg }}$ cells may indicate more focused production and peripheral proliferation with narrowed antigenic specificities in an individual MHCII context. This could be a possible consequence of the lack of $\mathrm{B}$ cells presenting a wide range of self and commensal antigens both in the thymus and on the periphery for naive $\mathrm{T}_{\text {reg }}$ positive selection and further tonic signaling, which is strongly required for $\mathrm{T}_{\text {reg }}$ homeostasis (35). Altogether, the decline in the naïve $\mathrm{T}_{\text {reg }}$ proportion among nCD4 ${ }^{+}$cells (Figure 1C), increased repertoire convergence (Figure 3A) and decreased diversity suggest impaired thymic $\mathrm{T}_{\text {reg }}$ selection in XLA patients, accompanied by biased peripheral proliferation.

The average CDR3 $\beta$ length was shorter in all $\mathrm{nCD} 4^{+} \mathrm{T}$ cell subsets ( $\mathrm{mnCD}^{+}$, RTE and naïve $\mathrm{T}_{\text {reg }}$ cells) of XLA individuals compared to healthy young donors (Figure $\mathbf{4 A}$ ). Additionally, the average number of random nucleotides inserted between $V \beta$ $D \beta$ and $D \beta-J \beta$ segments in CDR3 $\beta$ was smaller in RTEs and naïve $\mathrm{T}_{\text {reg }}$ cells (Figure 4B). It indicated limited capacity for conformational changes of $\mathrm{CDR} 3 \beta$ in $\mathrm{XLA} \mathrm{nCD}^{+}$repertoires, potentially reflecting more stringent selection. Shortening of CDR3 $\beta$ length in naive conventional repertoires also occurred in aged healthy individuals (Figures 4A, B) (20). In this respect, the repertoires of the XLA cohort resembled those of elderly individuals.

We next evaluated the physicochemical landscape of TCR repertoires for the $\mathrm{nCD} 4^{+} \mathrm{T}$ cell subsets. The amino acid properties of XLA CDR3 $\beta$ differed substantially from agematched healthy donors, although the extent of the differences depended on the cell type (Figures 4C-F). In particular, the CDR3 $\beta$ repertoires of both RTE and $\mathrm{mnCD}^{+}$subsets from XLA patients were characterized by increased numbers of strongly interacting amino acid residues (Figure 4C), supporting the results obtained for the entire pool of $\mathrm{nCD} 4^{+} \mathrm{T}$ cells (Figure 2C). Thus, the difference in strength between $\mathrm{mnCD} 4^{+}$cells and naïve $\mathrm{T}_{\text {reg }}$ cells was decreased in XLA individuals (Figure 4D) potentially reducing the average capacity of $\mathrm{T}_{\text {regs }}$ to suppress activated conventional $\mathrm{CD} 4^{+} \mathrm{T}$ cells. High-affinity TCRs allow $\mathrm{T}_{\text {reg }}$ cells to compete efficiently and in an antigen-specific fashion with conventional $\mathrm{T}$ cells for binding to peptide-MHC complexes presented by APCs $(36,37)$. Recent data have demonstrated that TCR-specific interactions may be one of the possible suppression mechanisms exerted by $\mathrm{T}_{\text {regs }}(37-39)$. 
A

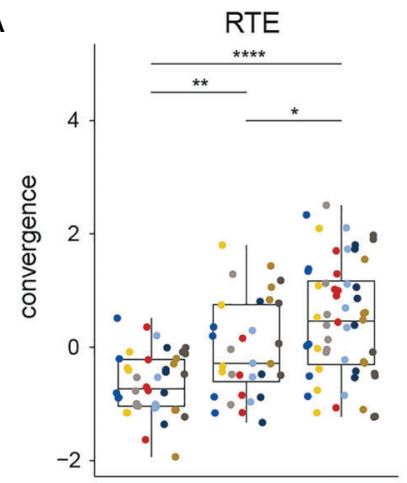

B

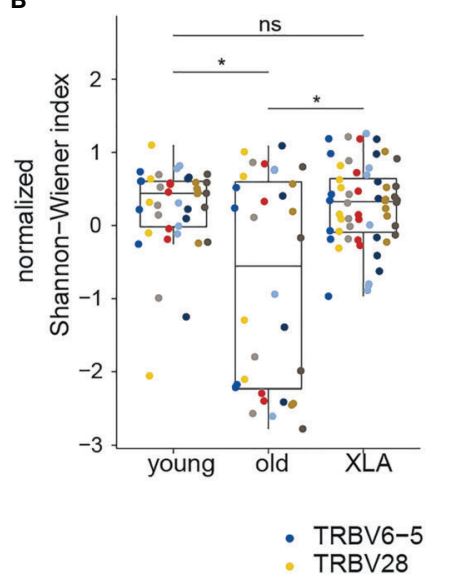

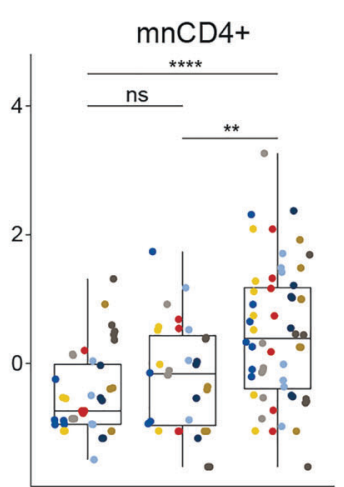
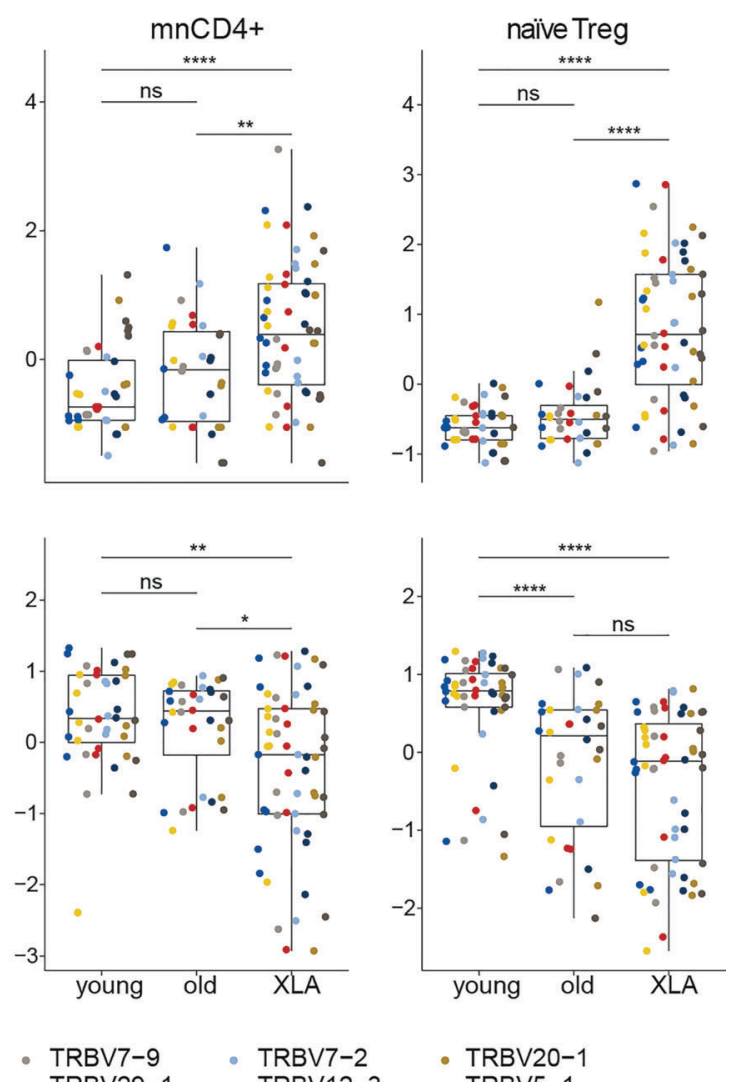

- TRBV12-3

- TRBV20-1

- TRBV5-1

c

RTE

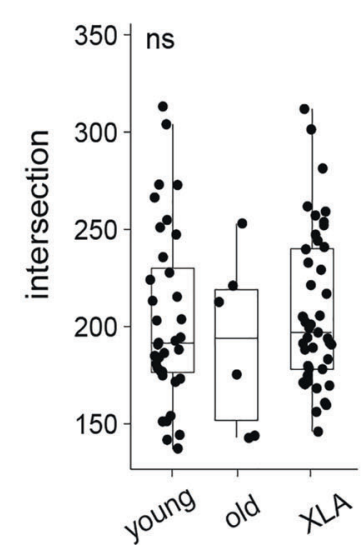

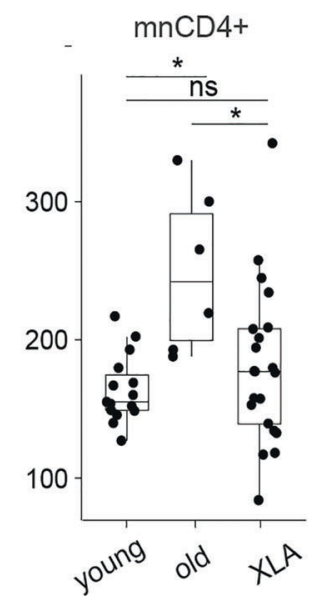

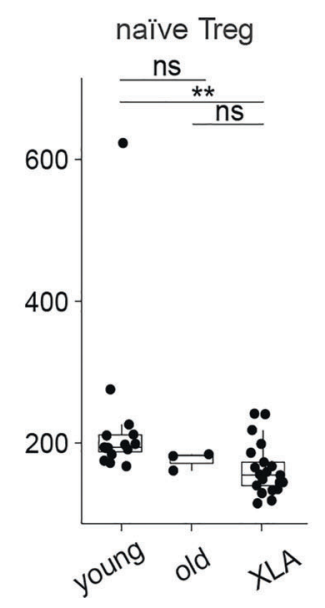

FIGURE 3 | Diversity and convergence of TCR $\beta$ repertoires of naiive CD4 ${ }^{+}$subsets in healthy donors and patients with XLA. Analysis of (A) convergence and (B) normalized Shannon-Wiener index in $\mathrm{nCD}^{+}$subsets (RTE, $\mathrm{mnCD}^{+}$, naïve $\mathrm{T}_{\text {reg }}$ ) in young and old healthy donors and in young $\mathrm{XLA}$ patients. Values were obtained for highly abundant TRBV gene segment groups and normalized to mean deviation. For the RTEs, the top 1,524 UMI-labelled sequences were analyzed for every TRBV segment. Donors Y13 and X10 were excluded because of insufficient coverage; this analysis included 8 young healthy donors, 4 old healthy donors, and 6 $\mathrm{XLA}$ donors. For the $\mathrm{mnCD4}^{+}, 1,063 \mathrm{UMI}$-labelled sequences were analyzed for every TRBV segment. Donors $\mathrm{Y} 8, \mathrm{Y} 13$, and X10 were excluded, and this analysis included 7 young healthy donors, 4 old healthy donors, and 6 XLA donors. For $T_{\text {reg, }}, 953$ UMI-labelled sequences were analyzed for every TRBV segment. Donors $\mathrm{X} 8, \mathrm{X} 9, \mathrm{X10}, \mathrm{Y} 8, \mathrm{Y} 10, \mathrm{Y} 11$ were excluded due to insufficient coverage, and this analysis included 6 young healthy donors, 4 old healthy donors, and $4 \mathrm{XLA}$ donors. Significance of median differences was evaluated by Dunn test. The false discovery rate was controlled using the Benjamini-Hochberg adjustment. ${ }^{*} p<0.05$, ${ }^{*} p<$ $0.01,{ }^{* * \star *} \mathrm{p}<0.0001$, ns, non significant. (C) Shows the number of shared public clonotypes between pairs of samples based on CDR3 amino acid sequences, from the 13,000 most abundant clonotypes in each cell subpopulation (for young donors, $N=9$ for $R T E$ and $m n C D 4^{+}$, and $N=6$ for naiive $T_{\text {reg; }}$ for old donors, $N=4$ for RTE and $\mathrm{mnCD4}^{+}$, and $\mathrm{N}=3$ for naïve $\mathrm{T}_{\text {reg; }}$; for $X L A$ patients, $\mathrm{N}=10$ for $\mathrm{RTE}$ and $\mathrm{mnCD4}^{+}$, and $\mathrm{N}=7$ for naïve $\mathrm{T}_{\text {reg }}$ ). All samples were down-sampled to the same number of UMls $\left(23,000 \mathrm{mnCD}^{+}, 24,000 \mathrm{RTE}, 31,000\right.$ naïv $\left.\mathrm{T}_{\text {reg }}\right)$. NS, non significant. 


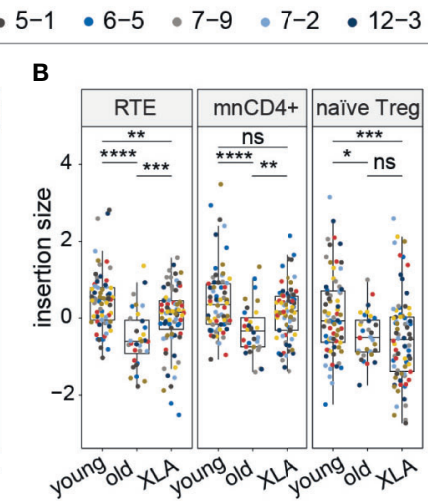

- 20-1 - 28 -29-1

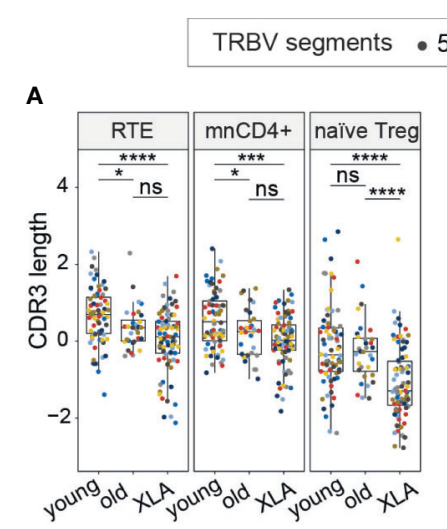

A

D
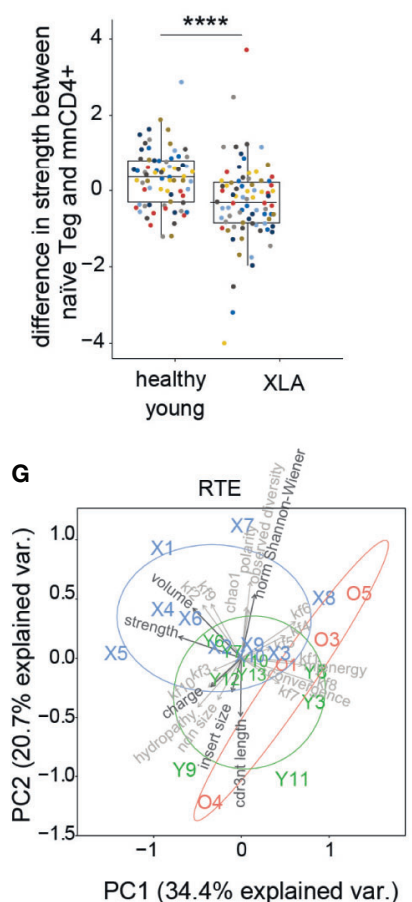

E

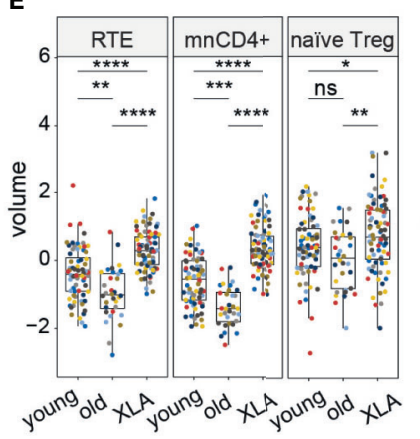

c

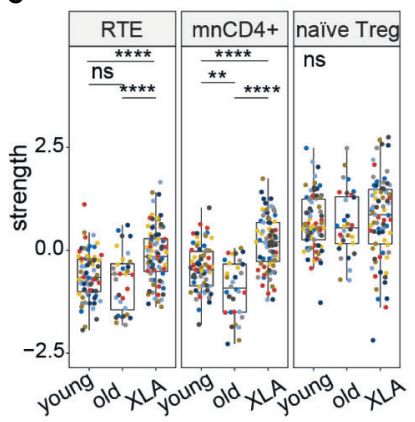

F

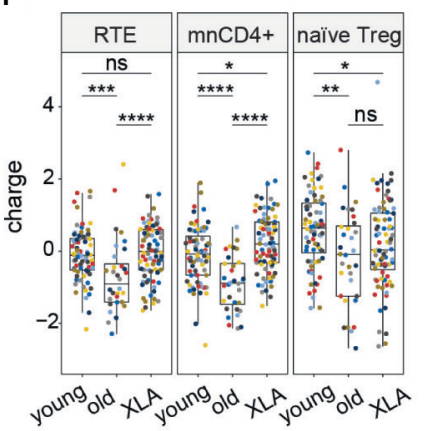

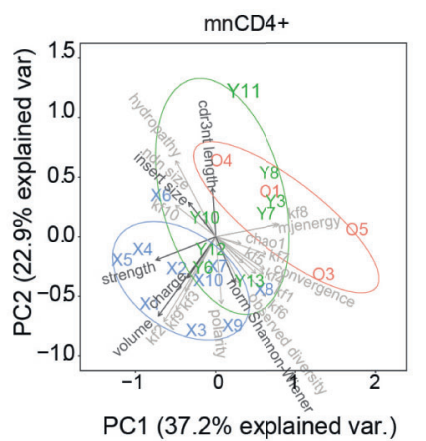

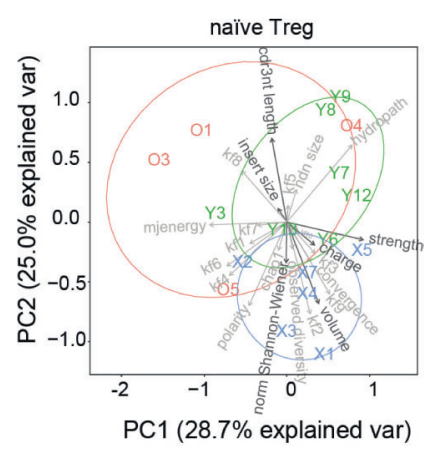

FIGURE 4 | CDR3 characteristics of TCR $\beta$ repertoires of naïve CD4 ${ }^{+}$subsets in healthy donors and XLA patients. (A) CDR3 $\beta$ length, (B) added nucleotides in CDR3 $\beta$ for the most abundant $V$ segments for full clonotype datasets, (C) estimated average number of strongly-binding amino acids in the central region of CDR3 for nCD4 ${ }^{+}$populations in XLA and healthy donors. (D) The difference in CDR3 $\beta$ interaction strength between naïve $\mathrm{T}_{\text {reg }}$ and mnCD4 ${ }^{+}$cell repertoires. (E) Estimated average number of bulky amino acids, and (F) charged amino acids in the central region of CDR3 for nCD4 ${ }^{+}$populations from XLA and healthy young or old donors. The number of healthy young, old and XLA donors was 9, 4 and 10 respectively. For panels (A-F), statistical significance of median differences was evaluated by Dunn test controlled using the Benjamini-Hochberg adjustment. Only segments with a sufficient number of UMls were included. To exclude potential dependence of features from the $V$ segment, all features within the same cell type and the same $V$ segment were turned to Z-scores. Differences between groups were assessed using the Kruskal-Wallis test followed by Dunn test, with the Benjamini-Hochberg stepwise adjustment. ${ }^{*} p<0.05$, ${ }^{* *} p<0.01$, ${ }^{\star * *} p<0.001$. (G) Principal component analysis (PCA) of nCD4 ${ }^{+}$subsets based on 23 TCR repertoire characteristics. PC1 is the first principal component, PC2 is the second. Each dot represents an individual TCR repertoire sample. Arrows in bold show properties from A-F and normalized Shannon-Wiener index. NS, non significant.

Repertoires from all XLA nCD4 ${ }^{+}$subsets differed from their counterparts in young healthy individuals in having an increased average number of bulky amino acid residues in the central region of $\mathrm{CDR} 3 \beta$ (Figure $4 \mathrm{E}$ ). Additionally, $\mathrm{mnCD} 4^{+} \mathrm{T}$ cells have a more charged CDR3 $\beta$ region in XLA patients than in healthy donors (Figure $\mathbf{4 F}$ ). In contrast, naïve $\mathrm{T}_{\text {regs }}$ in this group have decreased mean charge within the CDR3 $\beta$ region. The abovementioned shortening of CDR3 $\beta$ might be partially compensated at the expense of a high frequency of bulky amino acid residues within CDR3 $\beta$ in the XLA patient repertoires. Notably, we have shown previously that $\operatorname{CDR} 3 \beta$ domains from $\mathrm{mnCD} 4^{+} \mathrm{T}$ cells tend to have smaller numbers of strongly interacting and bulky amino acid residues in aged individuals (20), a finding that we have confirmed here (Figure 4). 
However, we observed the opposite in XLA patients, suggesting an association with $B$ cell deficiency rather than general immunosenescence. In other words, the differences in the $\mathrm{nCD}^{+}$TCR repertoire indicate that the specific process of $\mathrm{T}$ cell selection-but not the early exhaustion of naive $\mathrm{T}$ cell pools by pathogen burden-triggers these differences in XLA patients.

We next applied principal component analysis to the nCD4+ TCR $\beta$ repertoires of young healthy donors and XLA patients that revealed major contributing parameters, including the CDR3 length and average number of bulky amino acid residues, and illustrated the profound divergence of CDR3 $\beta$ repertoire characteristics between healthy donors and XLA patients (Figure 4G).

\section{Perturbation of Naïve $T_{\text {reg }}$ Programs}

To get insights on the functional alterations of $\operatorname{mnCD} 4^{+}$and naïve $\mathrm{T}_{\text {reg }}$ cell subsets, we performed transcriptomic analysis of these subsets from XLA and healthy young donors (Figure 5). Despite the fact that the $\mathrm{mnCD} 4^{+}$cells showed a significant change in the physicochemical properties of their TCR repertoires, we observed no essential changes in their transcriptome (Figure 5D).

We evaluated classical $\mathrm{T}_{\text {reg }}$ signatures of gene expression (e.g., FOXP3, IL2RA, TIGIT, CEACAM4, RTKN2) in the sorted naïve $\mathrm{T}_{\text {reg }}$ cells in comparison to $\mathrm{mnCD} 4^{+}$cells from XLA and healthy donors (Figures 5A, B). XLA naïve $\mathrm{T}_{\text {regs }}$ maintained comparable expression of $\mathrm{T}_{\text {reg }}$ phenotype-specific genes to healthy donors
(Figure 5C) as well as T-cell-specific genes (Supplemental Figure S4). Functionally distinct $\mathrm{T}_{\text {reg }}$ subsets that can be identified based on expression of certain transcription factors (i.e., Bcl6, Stat4, Stat3, T-bet, RORC) (40) and chemokine receptors (i.e., CCR6, CXCR3) (41) were also not overrepresented in XLA naïve $\mathrm{T}_{\text {reg }}$ relative to healthy donors.

Nevertheless, we found several atypical transcriptomic features of XLA naïve $\mathrm{T}_{\text {reg }}$ in comparison to healthy donors. Among 39 gene transcripts enriched in XLA naïve $T_{\text {reg }}$ were genes that are abundantly expressed by antigen-presenting cells (APCs) and myeloid cells, including IL1b, SECTM1, CD33, LILRB3, PILRA, NCF1, and TACI (Figures 5E-H). TACI, also known as $T N F R S F 13 B$, is a receptor for a proliferation-inducing ligand (APRIL) and B cell-activating factor of the tumor necrosis factor family (BAFF) (42), which is predominantly expressed on B cells. Recent evidence indicates that TACI expression in $\mathrm{T}_{\text {reg }}$ cells promotes their survival and proliferation (43), and the upregulation of TACI in XLA naïve $\mathrm{T}_{\text {reg }}$ cells suggests a mechanism of homeostatic naïve $\mathrm{T}_{\text {reg }}$ expansion in $\mathrm{B}$ celldeficient conditions. Several genes enriched in XLA cell populations (e.g., SECTM1, CD58) encode co-stimulatory molecules involved in T cell activation $(44,45)$. CD58 is widely expressed by both hematopoietic and non-hematopoietic cells, including B lymphocytes (46). The functional outcome of CD58$\mathrm{CD} 2$ interaction in $\mathrm{CD}^{+} \mathrm{T}$ cells remains poorly understood,
A

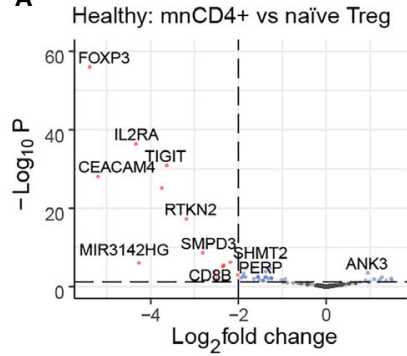

C

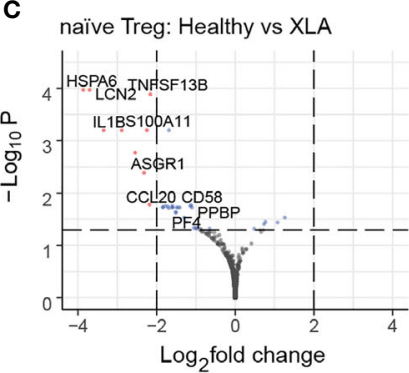

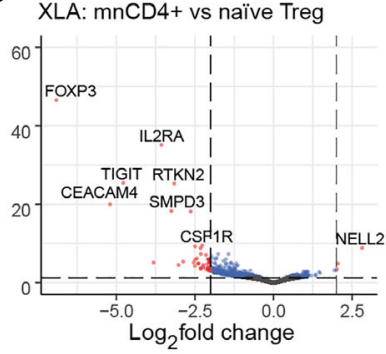

D

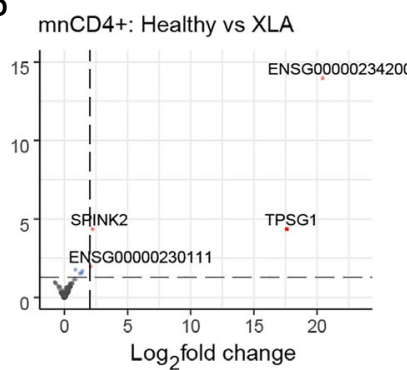

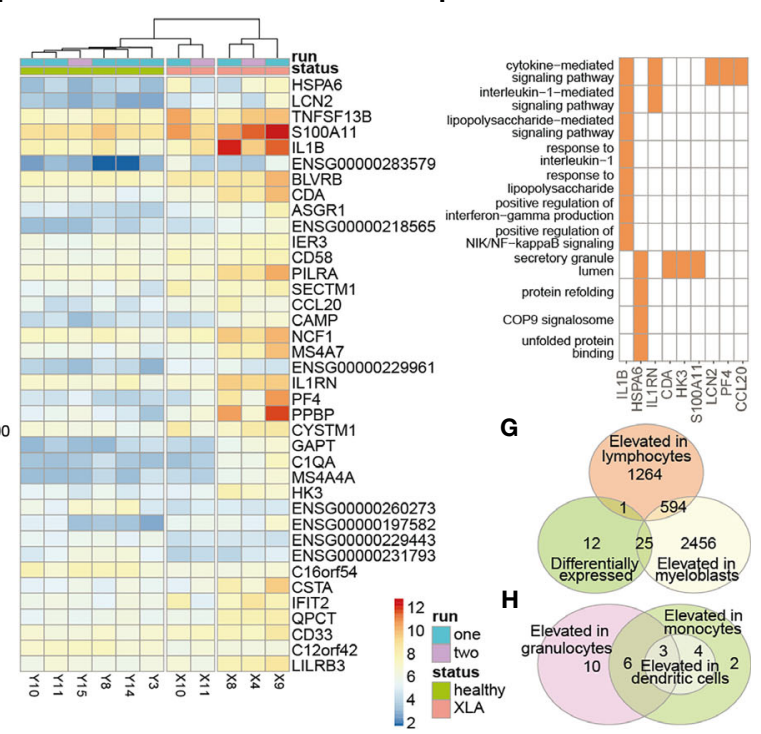

FIGURE 5 | Gene expression analysis in naïve $\mathrm{T}_{\text {regs. }}$. Differential gene expression analysis of naïve $\mathrm{T}_{\text {regs }}$ and $\mathrm{mnCD} 4^{+}$subpopulations in healthy donors (A) and patients with XLA (B) was performed using DESeq2. Red and blue dots show differentially expressed genes based on $p_{\text {adj }}<0.05$; red dots indicate transcripts based on absolute value of log2 fold changes $>2$. Adjusted $\mathrm{P}$ values were obtained using the Benjamini-Hochenberg procedure. Shrunken log2 fold changes were calculated using the ashr estimator, with $\mathrm{mnCD}^{+}$gene expression as numerator and naiive $\mathrm{T}_{\text {reg }}$ gene expression as denominator. (C) Differential gene expression analysis of naiive $\mathrm{T}_{\text {reg }}$ and (D) $\mathrm{mnCD}^{+}$with the healthy group as numerator and $\mathrm{XLA}$ as denominator. Colored dots highlight transcripts overexpressed in XLA naiive $T_{\text {reg }}\left(p_{\text {adj }}<0.05\right)$, red dots mark genes with log2 fold changes $>2$. (E) Heatmap of differentially expressed genes for naïve $T_{\text {reg }}$ cells from XLA and healthy donors. Data was prepared by DEseq2 as described in the Material and Methods section. (F) GO-enriched terms and input genes that are highly expressed in XLA naïve $T_{\text {reg. }}$. Enrichment analysis was performed by pathfindR package, with 0.05 threshold for $p$-adj following DESeq analysis. (G) Venn diagram of XLA naiive $T_{\text {reg }}$ differentially expressed transcripts, showing intersection with genes that are usually expressed in myeloblasts or lymphocytes, or $(\mathbf{H})$ intersection with genes usually elevated in granulocytes, dendritic cells, or monocytes according to www.proteinatlas.org. 
but this interaction with CD2 on NK and effector T cells has been shown to contribute to T cell proliferation and NK cell activation (47). Importantly, it can also induce rapid differentiation to an antigen-specific $\mathrm{T}_{\text {reg }}$ cell subtype, $\operatorname{Tr} 1$, that is characterized by high IL-10 production (48). Thus, CD58 upregulation in XLA might provide additional positive feedback stimulation of $\mathrm{T}_{\text {reg }}$ cells.

Interestingly, we also found enrichment of chemokine genes in the XLA naive $\mathrm{T}_{\text {reg }}$ transcriptome, including CCL20, CXCL4 (PF4), and PPBP (CXCL7) (Figures 5E, F). CXCL4 has been shown to exert Th17 induction in autoimmune diseases (49). Expression of CCL20 was previously reported in Tfh and Th17 cells and at very low levels in $\mathrm{T}_{\text {regs }}$, where the latter is mediated synergistically by TGF- $\beta$ /IL-6 (50).

Our data may indicate that peripheral maturation of XLA naïve $\mathrm{T}_{\text {reg }}$ cells occur under pro-inflammatory conditions that promote aberrant expression of proinflammatory markers and mediators (e.g., IL1b, CXCL4, CCL20 and S100A11) (49, 51). Interestingly, we also detected several atypically expressed genes that are normally specific to dendritic cells and granulocytes (Figures 5G, H). For example, $I L 1 b$ expression by lymphoid cells is not typical, although it has been described previously for CCR $5^{+} \mathrm{CD} 4^{+} \mathrm{T}$ cells (52). Our data assume that enhanced S100A11 and IER3 gene expression might be related to ILIb levels in XLA patients. IL1b-dependent up-regulation of IER3 has been reported to increase $\mathrm{T}$ cell lifespan (53), hinting at possible changes in naïve $\mathrm{T}_{\text {reg }}$ homeostasis in XLA donors.

\section{CONCLUSION}

Recent studies on primary immunodeficiency highlight critical gaps in current knowledge about how the TCR repertoire is shaped in the absence of B cells. Our study suggests that one of the most essential impacts of congenital $\mathrm{B}$ cell deficiency on the $\mathrm{T}$ cell branch of the immune system is on $\mathrm{nCD}^{+}{ }^{+} \mathrm{T}$ cell subsets, and especially on naïve $\mathrm{T}_{\text {reg }}$ selection and homeostasis. Specifically, we observed the decline in the naïe $\mathrm{T}_{\text {reg }}$ proportion among nCD $4^{+}$cells, increased convergence and clonality of the naïve $\mathrm{T}_{\text {reg }}$ TCR repertoire, specific differences in the averaged CDR3 $\beta$ characteristics of $\mathrm{nCD}^{+}$subsets that are distinct from those that accumulate with aging, and some notable alterations in the naïve $\mathrm{T}_{\text {reg }}$ transcriptome. Collectively, these findings indicate potential alterations in the selection, maturation, and peripheral proliferation of naïve $T_{\text {regs }}$ in XLA patients. Further studies with a wider methodical arsenal and larger patient cohorts will be required to confirm our findings and better elucidate the nature of the observed phenomena, but our results indicate that the intimate relationship between $\mathrm{B}$ cell and $\mathrm{T}_{\text {reg }}$ subsets (17) should remain the active focus of current investigations.

\section{REFERENCES}

1. LeBien TW, Tedder TF. B Lymphocytes: How They Develop and Function. Blood (2008) 112(5):1570-80. doi: 10.1182/blood-2008-02-078071

2. Cepeda S, Cantu C, Orozco S, Xiao Y, Brown Z, Semwal MK, et al. AgeAssociated Decline in Thymic B Cell Expression of Aire and Aire-Dependent Self-Antigens. Cell Rep (2018) 22(5):1276-87. doi: 10.1016/j.celrep.2018.01.015

\section{DATA AVAILABILITY STATEMENT}

The datasets presented in this study can be found in online repositories. The names of the repository/repositories and accession number(s) can be found below: https://www.ncbi. nlm.nih.gov/sra/, PRJNA752656, PRJNA752868; https:// figshare.com/articles/dataset/Na_ve_Regulatory_T_Cell_ Subset_Is_Altered_in_X-Linked_Agammaglobulinemia/ 15128715; https://figshare.com/articles/dataset/Untitled_ Item/15131340.

\section{ETHICS STATEMENT}

The studies involving human participants were reviewed and approved by NRC Institute of Immunology FMBA (Moscow, Russia), protocol 6-1, 09 June 2020. The patients/participants provided their written informed consent to participate in this study.

\section{AUTHOR CONTRIBUTIONS}

OB, DC, SL, MK, and IK designed research. TN, SK, VK, EE, DS, IS and EM performed research. PS, KL, VK analyzed data. EL and IM collected patient samples. DC, PS, KL, and OB wrote the paper. All authors contributed to the article and approved the submitted version.

\section{FUNDING}

The work was supported by grant of the Ministry of Science and Higher Education of the Russian Federation № 075-15-2020-807.

\section{ACKNOWLEDGMENTS}

Cell sorting experiments were carried out using the equipment provided by the IBCH Core facility. We are grateful to $\mathrm{M}$. Eisenstein for the English editing.

\section{SUPPLEMENTARY MATERIAL}

The Supplementary Material for this article can be found online at: https://www.frontiersin.org/articles/10.3389/fimmu.2021. 697307/full\#supplementary-material

3. Perera J, Meng L, Meng F, Huang H. Autoreactive Thymic B Cells Are Efficient Antigen-Presenting Cells of Cognate Self-Antigens for T Cell Negative Selection. Proc Natl Acad Sci USA (2013) 110(42):17011-6. doi: $10.1073 /$ pnas. 1313001110

4. Frommer F, Waisman A. B Cells Participate in Thymic Negative Selection of Murine Auto-Reactive CD4+ T Cells. PloS One (2010) 5(10):e15372. doi: 10.1371 /journal.pone.0015372 
5. Yamano T, Nedjic J, Hinterberger M, Steinert M, Koser S, Pinto S, et al. Thymic B Cells Are Licensed to Present Self Antigens for Central T Cell Tolerance Induction. Immunity (2015) 42(6):1048-61. doi: 10.1016/ j.immuni.2015.05.013

6. Lee YN, Frugoni F, Dobbs K, Tirosh I, Du L, Ververs FA, et al. Characterization of $\mathrm{T}$ and B Cell Repertoire Diversity in Patients With RAG Deficiency. Sci Immunol (2016) 1(6):eaah6109. doi: 10.1126/ sciimmunol.aah6109

7. Zhang J, Shehabeldin A, da Cruz LA, Butler J, Somani AK, McGavin M, et al. Antigen Receptor-Induced Activation and Cytoskeletal Rearrangement Are Impaired in Wiskott-Aldrich Syndrome Protein-Deficient Lymphocytes. J Exp Med (1999) 190(9):1329-42. doi: 10.1084/jem.190.9.1329

8. Ramesh M, Simchoni N, Hamm D, Cunningham-Rundles C. HighThroughput Sequencing Reveals an Altered T Cell Repertoire in X-Linked Agammaglobulinemia. Clin Immunol (2015) 161(2):190-6. doi: 10.1016/ j.clim.2015.09.002

9. Geginat J, Paroni M, Maglie S, Alfen JS, Kastirr I, Gruarin P, et al. Plasticity of Human CD4 T Cell Subsets. Front Immunol (2014) 5:630. doi: 10.3389/ fimmu.2014.00630

10. Cunningham CA, Helm EY, Fink PJ. Reinterpreting Recent Thymic Emigrant Function: Defective or Adaptive? Curr Opin Immunol (2018) 51:1-6. doi: $10.1016 /$ j.coi.2017.12.006

11. Friesen TJ, Ji Q, Fink PJ. Recent Thymic Emigrants Are Tolerized in the Absence of Inflammation. J Exp Med (2016) 213(6):913-20. doi: 10.1084/ jem. 20151990

12. Sakaguchi S, Sakaguchi N, Asano M, Itoh M, Toda M. Immunologic SelfTolerance Maintained by Activated T Cells Expressing IL-2 Receptor AlphaChains (CD25). Breakdown of a Single Mechanism of Self-Tolerance Causes Various Autoimmune Diseases. J Immunol (1995) 155(3):1151-64.

13. Kasatskaya SA, Ladell K, Egorov ES, Miners KL, Davydov AN, Metsger M, et al. Functionally Specialized Human CD4(+) T-Cell Subsets Express Physicochemically Distinct TCRs. eLife (2020) 9:e57063. doi: 10.7554/ eLife. 57063

14. Feng Y, van der Veeken J, Shugay M, Putintseva EV, Osmanbeyoglu HU, Dikiy S, et al. A Mechanism for Expansion of Regulatory T-Cell Repertoire and Its Role in Self-Tolerance. Nature (2015) 528(7580):132-6. doi: 10.1038/nature16141

15. Hernandez-Trujillo VP, Scalchunes C, Cunningham-Rundles C, Ochs HD, Bonilla FA, Paris K, et al. Autoimmunity and Inflammation in X-Linked Agammaglobulinemia. J Clin Immunol (2014) 34(6):627-32. doi: 10.1007/ s10875-014-0056-x

16. El-Sayed ZA, Abramova I, Aldave JC, Al-Herz W, Bezrodnik L, Boukari R, et al. X-Linked Agammaglobulinemia (XLA): Phenotype, Diagnosis, and Therapeutic Challenges Around the World. World Allergy Organ J (2019) 12(3):100018. doi: 10.1016/j.waojou.2019.100018

17. Tadmor T, Zhang Y, Cho HM, Podack ER, Rosenblatt JD. The Absence of B Lymphocytes Reduces the Number and Function of T-Regulatory Cells and Enhances the Anti-Tumor Response in a Murine Tumor Model. Cancer Immunol Immunother (2011) 60(5):609-19. doi: 10.1007/s00262-011-0972-z

18. Walters SN, Webster KE, Daley S, Grey ST. A Role for Intrathymic B Cells in the Generation of Natural Regulatory T Cells. J Immunol (2014) 193(1):170-6. doi: 10.4049/jimmunol.1302519

19. Lu FT, Yang W, Wang YH, Ma HD, Tang W, Yang JB, et al. Thymic B Cells Promote Thymus-Derived Regulatory T Cell Development and Proliferation. J Autoimmun (2015) 61:62-72. doi: 10.1016/j.jaut.2015.05.008

20. Egorov ES, Kasatskaya SA, Zubov VN, Izraelson M, Nakonechnaya TO, Staroverov DB, et al. The Changing Landscape of Naive T Cell Receptor Repertoire With Human Aging. Front Immunol (2018) 9:1618. doi: 10.3389/fimmu.2018.01618

21. Shugay M, Britanova OV, Merzlyak EM, Turchaninova MA, Mamedov IZ, Tuganbaev TR, et al. Towards Error-Free Profiling of Immune Repertoires. Nat Methods (2014) 11(6):653-5. doi: 10.1038/nmeth.2960

22. Sharapova SO, Pashchenko OE, Guryanova IE, Migas AA, Kondratenko IV, Aleinikova OV. Recent Thymic Emigrants, T Regulatory Cells, and BAFF Level in Children With X-Linked Agammaglobulinaemia in Association With Chronic Respiratory Disease. Allergol Immunopathol (Madr) (2018) 46(1):5866. doi: 10.1016/j.aller.2017.01.011

23. Martini H, Enright V, Perro M, Workman S, Birmelin J, Giorda E, et al. Importance of B Cell Co-Stimulation in $\mathrm{CD} 4(+) \mathrm{T}$ Cell Differentiation:
X-Linked Agammaglobulinaemia, a Human Model. Clin Exp Immunol (2011) 164(3):381-7. doi: 10.1111/j.1365-2249.2011.04377.x

24. Bateman EA, Ayers L, Sadler R, Lucas M, Roberts C, Woods A, et al. T Cell Phenotypes in Patients With Common Variable Immunodeficiency Disorders: Associations With Clinical Phenotypes in Comparison With Other Groups With Recurrent Infections. Clin Exp Immunol (2012) 170 (2):202-11. doi: 10.1111/j.1365-2249.2012.04643.x

25. Qi Q, Liu Y, Cheng Y, Glanville J, Zhang D, Lee JY, et al. Diversity and Clonal Selection in the Human T-Cell Repertoire. Proc Natl Acad Sci USA (2014) 111 (36):13139-44. doi: 10.1073/pnas.1409155111

26. Linton PJ, Harbertson J, Bradley LM. A Critical Role for B Cells in the Development of Memory CD4 Cells. J Immunol (2000) 165(10):5558-65. doi: 10.4049/jimmunol.165.10.5558

27. Crawford A, Macleod M, Schumacher T, Corlett L, Gray D. Primary T Cell Expansion and Differentiation In Vivo Requires Antigen Presentation by B Cells. J Immunol (2006) 176(6):3498-506. doi: 10.4049/jimmunol.176.6.3498

28. Whitmire JK, Asano MS, Kaech SM, Sarkar S, Hannum LG, Shlomchik MJ, et al. Requirement of B Cells for Generating CD4+ T Cell Memory. J Immunol (2009) 182(4):1868-76. doi: 10.4049/jimmunol.0802501

29. Paroli M, Accapezzato D, Francavilla V, Insalaco A, Plebani A, Balsano F, et al. Long-Lasting Memory-Resting and Memory-Effector CD4+ T Cells in Human X-Linked Agammaglobulinemia. Blood (2002) 99(6):2131-7. doi: 10.1182/blood.V99.6.2131

30. Kosmrlj A, Jha AK, Huseby ES, Kardar M, Chakraborty AK. How the Thymus Designs Antigen-Specific and Self-Tolerant T Cell Receptor Sequences. Proc Natl Acad Sci USA (2008) 105(43):16671-6. doi: 10.1073/pnas.0808081105

31. Logunova NN, Kriukova VV, Shelyakin PV, Egorov ES, Pereverzeva A, Bozhanova NG, et al. MHC-II Alleles Shape the CDR3 Repertoires of Conventional and Regulatory Naive CD4(+) T Cells. Proc Natl Acad Sci USA (2020) 117(24):13659-69. doi: 10.1073/pnas.2003170117

32. Stadinski BD, Shekhar K, Gomez-Tourino I, Jung J, Sasaki K, Sewell AK, et al. Hydrophobic CDR3 Residues Promote the Development of Self-Reactive T Cells. Nat Immunol (2016) 17(8):946-55. doi: 10.1038/ni.3491

33. Zinzow-Kramer WM, Weiss A, Au-Yeung BB. Adaptation by Naive CD4(+) T Cells to Self-Antigen-Dependent TCR Signaling Induces Functional Heterogeneity and Tolerance. Proc Natl Acad Sci USA (2019) 116 (30):15160-9. doi: 10.1073/pnas.1904096116

34. Nogueira JS, Canto FB, Nunes CF, Vianna PH, Paiva LS, Nobrega A, et al. Enhanced Renewal of Regulatory T Cells in Relation to CD4(+) Conventional T Lymphocytes in the Peripheral Compartment. Immunology (2016) 147 (2):221-39. doi: $10.1111 /$ imm.12555

35. Moran AE, Holzapfel KL, Xing Y, Cunningham NR, Maltzman JS, Punt J, et al. T Cell Receptor Signal Strength in Treg and iNKT Cell Development Demonstrated by a Novel Fluorescent Reporter Mouse. J Exp Med (2011) 208 (6):1279-89. doi: $10.1084 / \mathrm{jem} .20110308$

36. Ono M, Tanaka RJ. Controversies Concerning Thymus-Derived Regulatory T Cells: Fundamental Issues and a New Perspective. Immunol Cell Biol (2016) 94 (1):3-10. doi: 10.1038/icb.2015.65

37. Zhao J, Zhao J, Perlman S. Virus-Specific Regulatory T Cells Ameliorate Encephalitis by Repressing Effector T Cell Functions From Priming to Effector Stages. PloS Pathog (2014) 10(8):e1004279. doi: 10.1371/journal.ppat.1004279

38. Gubser C, Schmaler M, Rossi SW, Palmer E. Monoclonal Regulatory T Cells Provide Insights Into T Cell Suppression. Sci Rep (2016) 6:25758. doi: 10.1038/ srep 25758

39. Brincks EL, Roberts AD, Cookenham T, Sell S, Kohlmeier JE, Blackman MA, et al. Antigen-Specific Memory Regulatory CD4+Foxp3+ T Cells Control Memory Responses to Influenza Virus Infection. J Immunol (2013) 190 (7):3438-46. doi: 10.4049/jimmunol.1203140

40. Hua J, Davis SP, Hill JA, Yamagata T. Diverse Gene Expression in Human Regulatory T Cell Subsets Uncovers Connection Between Regulatory T Cell Genes and Suppressive Function. J Immunol (2015) 195(8):3642-53. doi: 10.4049/jimmunol.1500349

41. Plitas G, Konopacki C, Wu K, Bos PD, Morrow M, Putintseva EV, et al. Regulatory T Cells Exhibit Distinct Features in Human Breast Cancer. Immunity (2016) 45(5):1122-34. doi: 10.1016/j.immuni.2016.10.032

42. Wu Y, Bressette D, Carrell JA, Kaufman T, Feng P, Taylor K, et al. Tumor Necrosis Factor (TNF) Receptor Superfamily Member TACI Is a High Affinity 
Receptor for TNF Family Members APRIL and BLyS. J Biol Chem (2000) 275 (45):35478-85. doi: 10.1074/jbc.M005224200

43. Tai YT, Lin L, Xing L, Cho SF, Yu T, Acharya C, et al. APRIL Signaling Via TACI Mediates Immunosuppression by T Regulatory Cells in Multiple Myeloma: Therapeutic Implications. Leukemia (2019) 33(2):426-38. doi: 10.1038/s41375-018-0242-6

44. Wang T, Huang C, Lopez-Coral A, Slentz-Kesler KA, Xiao M, Wherry EJ, et al. K12/SECTM1, an Interferon-Gamma Regulated Molecule, Synergizes With CD28 to Costimulate Human T Cell Proliferation. J Leukoc Biol (2012) 91(3):449-59. doi: 10.1189/jlb.1011498

45. Kaizuka Y, Douglass AD, Vardhana S, Dustin ML, Vale RD. The Coreceptor CD2 Uses Plasma Membrane Microdomains to Transduce Signals in T Cells. J Cell Biol (2009) 185(3):521-34. doi: 10.1083/jcb.200809136

46. Bigot J, Pilon C, Matignon M, Grondin C, Leibler C, Aissat A, et al. Transcriptomic Signature of the CD24(hi) CD38(hi) Transitional B Cells Associated With an Immunoregulatory Phenotype in Renal Transplant Recipients. Am J Transplant (2016) 16(12):3430-42. doi: 10.1111/ajt.13904

47. Wang ECY, Pjechova M, Nightingale K, Vlahava VM, Patel M, Ruckova E, et al. Suppression of Costimulation by Human Cytomegalovirus Promotes Evasion of Cellular Immune Defenses. Proc Natl Acad Sci USA (2018) 115 (19):4998-5003. doi: 10.1073/pnas.1720950115

48. Wakkach A, Cottrez F, Groux H. Differentiation of Regulatory T Cells 1 Is Induced by CD2 Costimulation. J Immunol (2001) 167(6):3107-13. doi: 10.4049/jimmunol.167.6.3107

49. Affandi AJ, Silva-Cardoso SC, Garcia S, Leijten EFA, van Kempen TS, Marut W, et al. CXCL4 Is a Novel Inducer of Human Th17 Cells and Correlates With IL-17 and IL-22 in Psoriatic Arthritis. Eur J Immunol (2018) 48(3):522-31. doi: $10.1002 /$ eji.201747195

50. Yamazaki T, Yang XO, Chung Y, Fukunaga A, Nurieva R, Pappu B, et al. CCR6 Regulates the Migration of Inflammatory and Regulatory T Cells. J Immunol (2008) 181(12):8391-401. doi: 10.4049/jimmunol.181.12.8391
51. Andres Cerezo L, Sumova B, Prajzlerova K, Veigl D, Damgaard D, Nielsen $\mathrm{CH}$, et al. Calgizzarin (S100A11): A Novel Inflammatory Mediator Associated With Disease Activity of Rheumatoid Arthritis. Arthritis Res Ther (2017) 19 (1):79. doi: 10.1186/s13075-017-1288-y

52. Pulugulla SH, Packard TA, Galloway NLK, Grimmett ZW, Doitsh G, Adamik J, et al. Distinct Mechanisms Regulate IL1B Gene Transcription in Lymphoid CD4 T Cells and Monocytes. Cytokine (2018) 111:373-81. doi: 10.1016/ j.cyto.2018.10.001

53. Arlt A, Schafer H. Role of the Immediate Early Response 3 (IER3) Gene in Cellular Stress Response, Inflammation and Tumorigenesis. Eur J Cell Biol (2011) 90(6-7):545-52. doi: 10.1016/j.ejcb.2010.10.002

Conflict of Interest: The authors declare that the research was conducted in the absence of any commercial or financial relationships that could be construed as a potential conflict of interest.

Publisher's Note: All claims expressed in this article are solely those of the authors and do not necessarily represent those of their affiliated organizations, or those of the publisher, the editors and the reviewers. Any product that may be evaluated in this article, or claim that may be made by its manufacturer, is not guaranteed or endorsed by the publisher.

Copyright (C) 2021 Shelyakin, Lupyr, Egorov, Kofiadi, Staroverov, Kasatskaya, Kriukova, Shagina, Merzlyak, Nakonechnaya, Latysheva, Manto, Khaitov, Lukyanov, Chudakov and Britanova. This is an open-access article distributed under the terms of the Creative Commons Attribution License (CC BY). The use, distribution or reproduction in other forums is permitted, provided the original author(s) and the copyright owner(s) are credited and that the original publication in this journal is cited, in accordance with accepted academic practice. No use, distribution or reproduction is permitted which does not comply with these terms. 